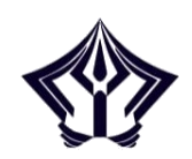

ANFUSINA: JOURNAL OF PSYCHOLOGY

http://ejournal.radenintan.ac.id/index.php/anfusina

DOI: //dx.doi.org/10.24042/ajp.v2i1.4154

Volume 2, Nomor 1, April Tahun 2019

\title{
Hubungan Antara Self Control Dengan Perilaku Berhutang Pada Mahasiswa Fakultas X Universitas Muhammadiyah Lampung
}

\begin{tabular}{c} 
Nurmalina \\
Universitas Muhammadiyah Lampung \\
Nurmalina1967@yahoo.com \\
Sulastri \\
Universitas Muhammadiyah Lampung \\
Sulastri2270@gmail.com \\
\hline
\end{tabular}

\begin{abstract}
This study aims to determine the relationship between self control and debt behavior to students of the Faculty of X Muhammadiyah Lampung University. The research hypothesis is that there is a relationship between self control and debt behavior to students of the Faculty of $X$ Muhammadiyah Lampung University. The variables used are indebted behavior and self control. Samples were students of the Faculty of $X$ Muhammadiyah University of Lampung by using purposive sampling technique. Data collection uses the scale of indebted behavior and self control with the data analysis method Pearson Correlation Analysis technique. The results of the study there is a significant negative relationship between self control and debts behavior Student X Faculty of Muhammadiyah University of Lampung (where the value of rxy $=-0.444$ and $\alpha=0.001$ where $\alpha<0.05$ ). the lower the self control behavior, the higher the debt owing behavior of the students of the Faculty of Muhammadiyah University of Lampung, X, on the contrary the higher the self-control behavior, the lower the debt behavior the students of Faculty of X Muhammadiyah University Lampung
\end{abstract}




\begin{abstract}
Abstrak
Penelitian ini bertujuan untuk mengetahui hubungan antara self control dengan perilaku berhutang pada Mahasiswa Fakultas X Universitas Muhammadiyah Lampung. Hipotesis penelitian adalah ada hubungan antara self control dengan perilaku berhutang pada mahasiswa Fakultas X Universitas Muhammadiyah Lampung. Variabel yang digunakan adalah perilaku berhutang dan self control. Sampel adalah Mahasiswa Fakultas X Universitas Muhammadiyah Lampung dengan menggunakan teknik purposive sampling. Pengumpulan data menggunakan skala perilaku berhutang dan self control dengan metode analisis data teknik Analysis korelasi Pearson.

Hasil penelitian ada hubungan yang signifikan negatif antara self control dengan perilaku berhutang Mahasiswa Fakultas X Universitas Muhammadiyah Lampung (dimana nilai $\mathrm{rxy}=-0,441$ dan $\alpha=0,001$ dimana $\alpha<0,05$ ).hubungan kedua variabel bersifat tidak searah dan bernilai negatif yang berarti bahwa semakin rendah prilaku self control maka semakin tinggi prilaku berhutang mahasiswa Fakultas $\mathrm{X}$ Universitas Muhammadiyah Lampung, sebaliknya semakin tinggi prilaku self control maka semakin rendah prilaku berhutang mahasiswa Fakultas $\mathrm{X}$ Universitas Muhammadiyah Lampung.
\end{abstract}

Keyword: Debt Behavior and Self Control

\title{
Pendahuluan
}

Indonesia adalah negara yang sedang berkembang dan memiliki berbagai macam tingkat permasalahan pada penduduknya, diantara adalah masalah-masalah yang berkembang di masyarakat yang menganggap mudah untuk berhutang karena permasalahan ekonomi. Berhutang telah menjadi pilihan terakhir bagi perilaku ekonomi masyarakat yang banyak digunakan untuk memenuhi kebutuhannya, perilaku berhutang tidak hanya dilakukan oleh masyarakat kelas menengah ke bawah tetapi dilakukan juga oleh individu menengah ke atas untuk memenuhi kebutuhannya.

Hutang sangat erat dengan pola kehidupan masyarakat Indonesia, hutang tidak hanya dillakukan oleh individu tetapi juga dilakukan oleh pemerintah Indonesia. Hutang adalah proses bagaimana perilaku meminjam dan mengembalikan uang dengan adanya perjanjian antara kedua pihak atau lebih, bisa dengan antara seseorang, bahkan dengan pihak lainnya. Keinginan untuk berutang timbul karena adanya kebutuhan tertentu yang melebihi pendapatan atau persediaan keuangan, baik untuk kebutuhan yang terencana maupun kebutuhan yang mendadak. 
Perilaku berhutang pada individu umumnya disebabkan oleh perilaku dirinya sendiri, tidak bisanya melakukan pengelolahan uang, tidak bisanya menahan diri ketika ingin memiliki suatu barang serta mengikuti gaya hidup di lingkungan sekitarnya. Perilaku berhutang tidak hanya terjadi pada individu yang telah berkeluarga saja, bahkan pelajar/mahasiswa yang hidup dan tinggal terpisah dari orang tuanya bukan hal asing lagi ketika mereka memiliki perilaku berhutang, ada yang hanya demi untuk bisa memenuhi kehidupan primer mereka sampai dengan memenuhi biaya kebutuhan sekunder mereka.

Mahasiswa sebagai individu yang sedang menimba ilmu pengetahuan di perguruan tinggi, baik perguruan tinggi negeri maupun perguruaan tinggi swasta. Mahasiswa dinilai memiliki tingkat kecerdasan dalam berpikir dan kerencanaan dalam bertindak serta memilliki intelektualitas yang tinggi. Sebagai mahasiswa, menjadi lebih mudah mengelola keuangan bisa mengatur pengeluran uang yang digunakan agar tidak menjadi boros dan kesulitan dalam membeli kebutuhan yang terkadang serba mendadak. Uang dapat mempengaruhi individu untuk berpikir dan bertindak secara rasional, sikap terhadap uang dapat memunculkan sifat negatif dan perilaku keserakahan, dendam, ketakutan serta perilaku berhutang.

Fenomena mahasiswa mempunyai masalah yang disebabkan prilaku berhutang,. Tidak jarang juga kasus perilaku berhutang mahasiswa di lingkungan sekitar, khususnya pada mahasiswa Fakultas X Universitas Muhammadiyah Lampung. Hasil dari wawancara awal dan observasi awal yang dilakukan terhadap mahasiswa semester 4-6 yang kepada salah satu dan teman-teman ( 27 April 2018). Terungkap bahwa perilaku berhutang banyak terjadi disebabkan oleh kurangnya atau keterbatasan uang saku yang diberikan oleh orang tua terhadap dirinya, buruknya kontrol diri dalam mengatur atau mengelola keuangan dengan tidak baik serta adanya pengaruh gaya hidup lingkungan sekitar, tanpa disadari sering sekali melakukan perilaku berhutang.

Hasil penelitian Prasadjaningsih (dalam Kukuh P.W, 2016), menunjukkan mayoritas subjek memiliki perilaku berhutang $63,1 \%$ yang didominasi oleh perempuan yang mencapai $69,2 \%$, sedangkan kelompok usia yang berhutang lebih didominasi oleh kelompok kawula muda $(56,9 \%)$ dibanding kelompok lainnya. Dari sisi pendidikan yang cenderung menunjukkan perilaku berhutang maupun tidak adalah pada kategori status mahasiswa, tamat sarjana muda (48\% yang berhutang, $40 \%$ tidak berutang) 
kelompok yang menampilkan gaya hidup materialitas tergolong kelompok yang menampilkan gaya hidup yang berfoya-foya.

Hasil penelitian Nugrahaini (dalam Kukuh P.W, 2016), menunjukkan kemunculan perilaku berhutang mahasiswa di Malang adalah 20\% disebabkan oleh faktor gaya hidup hedonis, sedangkan $80 \%$ disebabkan faktor lain seperti kiriman orang tua telat, jenis kelamin, faktor pribadi (usia terhadap siklus hidup, pekerjaan, lingkungan, ekonomi, kepribadian, dan konsep diri) faktor budaya, faktor psikologis (motivasi, persepsi, pembelajaan, dan sikap)

Menurut William (Yusuf, 2008) mahasiswa yang termasuk dalam bagian remaja akhir yang memiliki tugas perkembangan yaitu memperkuat self control (kemampuan mengendalikan diri) atas dasar skala nilai, prinsip-prinsip atau falsafah hidup. Pada usia tersebut, individu seperti meereka membutuhkan pengakuan dari lingkungan sekitar, masih dalam tahap pencarian jati diri dan masih dalam keadaan emosi yang labil. Keadaan tersebut cenderung membuat kontrol diri dapat melemah sehingga apapun yang menjadi keputusan individu lakukan termasuk keputusan berhutang didasari oleh kontrol diri yang tidak baik.

Mengelola keuangan pribadi bukanlah hal yang mudah mengingat terdapat beberapa kesulitan dalam pengelolaan keuangan diri sendiri. Faktanya, saat ini yang terjadi pada individu yaitu untuk melakukan pembelian barang bukan hanya karena kebutuhan tetapi karena faktor keinginan, gengsi, harga diri serta mengikuti gaya hidup orang lain, yang disebabkan kontrol diri individu yang tidak baik dalam melakukan pengelolahan uang yang dapat berdampak terhadap perilaku berhutang.

Masalah prilaku berhutang dapat diatasi atau tidak terjadi (salah satunya dan banyak faktor lain), apabila mahasiswa/i memiliki kontrol diri yang baik. Mahasiswa/i yang memiliki kontrol diri yang baik dapat memiliki kemampuan untuk menahan dan menekan tingkah laku sendiri. Kemampuan untuk menekan tingkah laku untuk berperilaku berhutang, yaitu dengan cara hidup yang bagaimana orang dapat menghabiskan waktu mereka atau aktivitas yang mereka anggap penting dalam lingkungannya (ketertarikan), dan apa yang mereka pikirkan tentang diri mereka sendiri dan juga dunia di sekitarnya untuk mengkonsumsi barangbarang yang sebenarnya tidak diperlukan demi kesenangan dan kenikmatan seolah sikap dan keberadaan tersebut merupakan simbol kebanggaan serta dapat menimbulkan perilaku berhutang.

Self control atau kontrol diri seperti yang dikemukakan oleh Averill (Kusumadewi, 2012) adalah kontrol diri merupakan 
variabel psikologis yang mencakup kemampuan individu untuk memodifikasi perilaku, kemampuan individu dalam mengelola informasi yang tidak penting atau penting dan kemampuan individu untuk memilih suatu tindakan yang diyakininya. Kontrol diri atau self control yang buruk dapat berakibat menjaadi salah satu faktor penyebab perilaku berhutang pada mahasiswa.

Berdasarkan yang telah dijelaskan di atas, mahasiswa dinilai penting memiliki self control atau kontrol diri yang baik, agar dapat mengendalikan diri dalam memanfaatkan keuangan dengan baik, sesuai kebutuhan dan terhindar dari perilaku berhutang yang dapat merugikan diri sendiri maupun orang lain. Sehingga penelitian ini bertujuan untuk mengetahui hubungan self control dengan perilaku berhutang pada mahasiswa Fakultas X Universitas Muhammadiyah Lampung.

\section{Metode Penelitian}

Penelitian ini menggunakan metode penelitian kuantitaif, dengan subyek penelitian adalah mahasiswa Fakultas X semester 5 dan 7, yang berjumlah 53 mahasiswa. Teknik yang digunakan dalam pengambilan sampel penelitian, dilakukan dengan cara menggunakan teknik sampling purposive. Yaitu teknik pengambilan sampel secara sengaja sesuai dengan persyaratan sampel yang diperlukan. Data penelitian ini diperoleh dengan menggunakan skala sikap model Likert yang terdiri dari skala prilaku berhutang dan skala self control.

Metode analisis data yang digunakan dalam penelitian ini adalah menggunakan teknik analisis korelasi Pearson. Metode analisis data yang digunakan untuk pengujian hipotesis dalam penelitian ini bertujuan untuk mencari apakah terdapat hubungan antara self control dengan perilaku berhutang pada mahasiswa. Pengukuran tersebut menggunakan teknik analisis korelasi Pearson yang digunakan yang akan dianalisis menggunakan progam Statistical for Social Science (SPSS) for windows.

\section{Hasil dan Pembahasan}

\section{Hasil Uji Analisis Alat Ukur}

a. Uji Validitas Intstrumen

Skala perilaku berhutang: Berdasarkan uji validitas terhadap skalaskala perilaku berhutang,ditemukan sebanyak 5 butir aitem yang dinyatakan gugur yaitu butir 
nomor $6,12,19,22$ dan 30, terdapat 25 butiraitem yang dinyatakan valid. Sebaran koefisien korelasi aitem-total (Corrected Item-Total Correlation),item skala perilaku berhutang bergerak dari 0,331 sampai 0,781 dengan taraf signifikansi $\alpha>0,05$.

Skala self control: Berdasarkan uji validitas terhadap skala self control,ditemukan sebanyak 2 buti raitem yang dinyatakan gugur yaitu butir nomor 5 dan 14 , terdapat 28 butiraitem yang dinyatakan valid.Sebaran koefisien korelasi aitem-total(Corrected Item-Total Correlation),item skala self control bergerak dari 0,364sampai0,769 dengan taraf signifikansi $\alpha>0,05$

\section{b. Uji Reliabilitas Instrumen}

Perhitungan reliabilitas pada skala perilaku berhutangdan self controlmenggunakan SPSS for windows diketahui bahwa koefisien reliabilitas alpha (Cronbach's alpha) pada skala perilaku berhutang adalah 0,916 dan padaskala self control adalah 0,929. Hal ini dapat dikatakan bahwa skala gaya hidup konsumtif dapat dikatakan reliable dan memiliki nilai reliabilitas yang sangat baik, koefisien reliabilitas skala yang kurang dari 0,6 dinilai kurang baik, koefisien reliabilitas 0,7 dapat diterim adan di atas 0,8 adalah baik (Priyatno, 2010).

\section{Uji Hipotesis}

Uji hipotesis dalam penelitian dilakukan dengan korelasi pearson dan regresi satu arah dalam aplikasi SPSS. Dalam korelasi pearson untuk dapat mengetahui kuat lemahnya atau derajat keeratan antara variabel-variabel yang diteliti digunakan tabel interpretasi koefisien korelasi sesuai dengan pendapat Sugiono ( 2014).

\section{Tabel 14.Interpretasi Koefisien Korelasi}

\begin{tabular}{cc}
\hline Interval Koefisien & Tingkat Hubungan \\
\hline $0,00-0,199$ & Sangat Rendah \\
$0,20-0,399$ & Rendah \\
$0,40-0,599$ & Sedang \\
$0,60-0,799$ & Kuat \\
$0,80-1000$ & Sangat Kuat \\
\hline
\end{tabular}


Hipotesis dalam penelitian ini adalah Ada hubungan antara self control dengan perilaku berhutangpada mahasiswa Fakultas X Universitas Muhammadiyah Lampung. Dari hasil uji hipotesis yang telah dilakukan diperoleh hasil sebagai berikut:

\section{Tabel 15. Uji Corelations}

\begin{tabular}{rrrr}
\hline & & Prilaku.Berhutang & Self.Control \\
\hline $\begin{array}{r}\text { Prilaku. } \\
\text { Berhut } \\
\text { ang }\end{array}$ & Pearson Correlation & 1 & $-0,441^{* *}$ \\
& Sig. (2-tailed) & 53 & 0,001 \\
\hline Self. & Pearson Correlation & $-0,441^{* *}$ & 53 \\
Control & Sig. (2-tailed) & 0,001 & 1 \\
& $\mathrm{~N}$ & 53 & 53 \\
\hline$* *$ Correlation is significant at the 0.01 level (2- \\
\end{tabular}

Berdasarkan output di atas di peroleh nilai koefisien korelasi sebesar $\mathrm{rxy}=-0,441$ dan nilai $\mathrm{p}=0,001$ karena nilai $\mathrm{p}<0,05$ maka hasil dari uji hiptesis adalah ada hubungan yang signifikan antara self control dengan perilaku berhutangpada mahasiswa Fakultas X Universitas Muhammadiyah Lampung. Karena nilai koefisien korelasi di atas adalah bernilai negatif (-) maka hubungan kedua variabel tersebut bersifat tidak searah, yang artinya semakin rendah perilaku self control maka semakin tinggi perilaku berhutang pada mahasiswa Fakultas X Universitas Muhammadiyah Lampung.

Berdasarkan hasil perhitungan hipotesis secara statistik dengan menggunakan teknik uji korelasi Pearson yang dibantu oleh program (SPSS) yang telah dilakukan, maka diperoleh hasil sebagai berikut : $r x y=-0,441$ dengan nilai $p=0,001$ karena $p<0,05$ maka dapat disimpulkan ada hubungan yang signifikan antara self control dengan perilaku berhutang pada mahasiswa Fakultas X Universitas Muhammadiyah Lampung.

Hubungan kedua variabel adalah bersifat tidak searah, karena nilai koefisien korelasi bernilai negatif (-) yang artinya hal ini menunjukkan semakin rendah prilaku self control maka semakin tinggi prilaku berhutang mahasiswa Fakultas $\mathrm{X}$ Universitas Muhammadiyah Lampung, sebaliknya semakin tinggi prilaku self control maka semakin rendah prilaku berhutang mahasiswa Fakultas X Universitas Muhammadiyah Lampung. 
Dapat diartikan bahwa variabel self control memiliki peran terhadap tinggi rendahnya prilaku berhutang seseorang.

Sejalan dengan pendapat Lazarus (dalam Utami \& Sumaryono,2008) bahwa adanya pengendalian diri menjadikan individu dapat mengarahkan, dan mengatur prilakunya dengan kuat dan pada akhirnya menuju pada konsekuensi positif. Konsekuensi yang dimaksud adalah mampu menekan kecenderungan perilaku berhutang.

Menurut William (Yusuf, 2008) mahasiswa yang termasuk dalam bagian remaja akhir yang memiliki tugas perkembangan yaitu memperkuat self control (kemampuan mengendalikan diri) atas dasar skala nilai, prinsip-prinsip atau falsafah hidup. Pada usia tersebut, individu seperti meereka membutuhkan pengakuan dari lingkungan sekitar, masih dalam tahap pencarian jati diri dan masih dalam keadaan emosi yang labil. Keadaan tersebut cenderung membuat kontrol diri dapat melemah sehingga apapun yang menjadi keputusan individu lakukan termasuk keputusan berhutang didasari oleh kontrol diri yang tidak baik.

Menurut Collins (dalam Kukuh, 2016) Perilaku berhutang adalah pengeluaran untuk konsumsi yang lebih besar daripada pendapatan, perbedaan ini dibayarkan dari tabungan sebelumnya. Berdasarkan teori tersebut individu akan melakukan perilaku berhutang ketika pengeluaran yang dialaminya mengalahkan pendapatan yang dia terima. Menurut Katona (1951), perilaku berhutangialah besar pengeluaran daripada pendapatan yang diterima.

Berdasarkan hasil analisis deskriptif pada tabel data deskriptif pada skala perilaku berhutang memperkuat hasil uji regresi diketahui bahwa perilaku berhutang relatif tinggi. Dimana dari 53 responden yang dijadikan sampel, terdapat 27 subjek yang memiliki perilaku berhutang yang tinggi dengan presentase 51\%, 17 subjek berada pada level sedang dengan presentase $32 \%$, sedangkan 9 subjek berada pada level rendah.

Pada tabel data deskriptif terhadap skala self controldiketahui bahwa skala self controlrelatif rendah. Berdasarkan data yang di dapat dari 53 subjek yang dijadikan sampel, terdapat 21 subjek memiliki self controlyang rendah dengan presentase 39,6\%, 19 subjek yang berada pada level sedang dengan presentase $35,9 \%$, dan self controlpada level tinggi terdapat 13 subyek dengan presentase $24,5 \%$. Hasil deskriptif, mendukung hasil uji hipotesis yang menunjukkan bahwa hipotesis terbukti, ditunjukkan bahwa perilaku berhutang berada pada level tinggi, self controlberada pada level rendah 


\section{Simpulan dan Saran}

Berdasarkan hasil penelitian tentang hubungan antara self control dengan perilaku berhutang pada mahasiswa Fakultas X Universitas Muhammadiyah Lampung yang telah dilakukan dan berdasarkan hasil analisis serta pembahasan yang telah diuraikan sebelumnya, dapat diketahui bahwa ada hubungan yang signifikan antara self control dengan perilaku berhutang pada mahasiswa Fakultas X Universitas Muhammadiyah Lampung. Ditandai dengan mayoritas Prilaku berhutang mahasiswa Fakultas $\mathrm{X}$ Universitas Muhammadiyah Lampung yang tinggi, dikarnakan rendahnya self controlpada diri mahasiswa.

Hasil analisis data yang dilakukan didapatkan nilai koefisien korelasi adalah -0.441 danp $=0,001$ menunjukkan bahwa nilai $\mathrm{p}<0,05$.Sehingga dapat disimpulkan bahwa ada hubungan signifikan negatif antara self control dengan perilaku berhutang pada mahasiswa Fakultas $\mathrm{Xi}$ Universitas Muhammadiyah Lampung, kedua variabel memiliki hubungan yang tidak searah dan bernilai negatif yang berarti bahwa semakin rendah prilaku self control maka semakin tinggi prilaku berhutang mahasiswa Fakultas X Universitas Muhammadiyah Lampung, sebaliknya semakin tinggi prilaku self control maka semakin rendah prilaku berhutang mahasiswa Fakultas X Universitas Muhammadiyah Lampung. Dapat diartika bahwa variabel self control memiliki peran terhadap tinggi rendahnya prilaku berhutang seseorang

\section{Referensi}

Azwar, S. 2012. Reliabilitas dan Validitas.Yogyakarta: Pustaka pelajar

.2013. Metode Penelitian. Yogyakarta: Pustaka Pelajar

Chaplin, J.P. 2002. Kamus Lengkap Psikologi. Jakarta: Raja Grafindo Persada

Gufron, M. 2011. Teori teori Psikologi. Yogyakarta: Ar-ruzz Media

Gunarsa, D. S. (2004). Psikologi Praktis: Dari Anak Sampai Usia Lanjut. Jakarta: PT.BPK Gunung Mulia. 
Hadi, S. 1993. Metodologi Research. Yogyakarta. Andi Offset.

Hornby, A. S. (1993). Oxford advanced learner's dictionary of current English. Fourth Edition. Oxford: Oxford University Press.

Hurlock, E. B. 1990. Psikologi Perkembangan.Jakarta:Erlangga.

Kukuh P.W. (2016). Hubungan Compulsive Buying Dengan Perilaku Berhutang (Dissaving). Skripsi.Malang : Universitas Muhammadiyah Malang

M Nur Ghufron dan Rini R S. 2011. Teori Teori Psikologi. Jogjakarta: Ar-ruzz Media.

Priyatno, Dwi. 2010. Cara Mudah dan Cepat Melakukan Analisis DataPenelitian. Yogya : Gava Media

Shohib, M. (2015). Sikap Terhadap Uang Dan Perilaku Berhutang.Skripsi.Tidak Diterbitkan. Malang: Universitas Muhammadiyah Malang.

Sugiyono, (2008). Metode Penelitian Kunatitatif Kualitatif dan R\&D. Bandung: Alfabeta.

2010. Metode Penelitian Pendidikan Pendekatan Kuantitatif, kualitatif, dan R\&D. Bandung: Alfabeta

2011. Metode Penelitian Kuantitatif, Kualitatif dan $R \& D$. Bandung: Afabeta

Utami, A.F dan Sumaryono. (2008). Pembelian Impulsif Ditinjau dari Kontrol Diri dan Jenis Kelamin pada Remaja. Jurnal Psikologi Proyeksi.

Yusuf, S. 2008. Psikologi Perkembangan Anak dan Remaja. Bandung : PT Remaja Rosdakary

Ajzen. I., 1991. The Theory of Planned Behaviour. In: Organizational Behaviour and Human Decision Process. Amherst, MA: Elsevier 